\title{
A fractal root model applied for estimating the root biomass and architecture in two tropical legume tree species
}

\author{
Eduardo SALAS ${ }^{\mathrm{a}}$, Harry OZIER-LAFONTAINE ${ }^{\mathrm{b}}$, Pekka NYGREN ${ }^{\mathrm{c} *}$ \\ a Escuela de Fitotecnia, Universidad de Costa Rica, Ciudad Universitaria “Rodrigo Facio", San Pedro de Montes de Oca, Costa Rica \\ b UR Agropédoclimatique, INRA, Centre Antilles-Guyane, Domaine Duclos, 97170 Petit Bourg, Guadeloupe, France \\ ${ }^{c}$ Department of Forest Ecology, PO Box 27, 00014 University of Helsinki, Finland
}

(Received 31 January 2003; accepted 20 August 2003)

\begin{abstract}
A fractal root model with parameter estimation based on pipe model theory was applied for studying root architecture of Erythrina lanceolata and Gliricidia sepium associated with crops in agroforestry. The results were compared with a theoretical volume-filling fractal model on scaling of plant vascular system. Scaling of root diameter at bifurcation followed same parameter values over the whole root system. The parameter values were approximately equal in both species. Length between two bifurcations could not be estimated according to volumefilling fractal principles, but an empirical regression was used. An empirical model was also applied for estimating bifurcation angles. These characteristics seem to respond strongly to local root environment, and their modelling calls for studying root-soil interactions. Agronomic applications of this study indicate the usefulness of an architectural approach for the study of belowground interactions in agroforestry systems.
\end{abstract}

Erythrina lanceolata / Gliricidia sepium / agroforestry / pipe model / self-similarity

Résumé - Application d'un modèle racinaire fractal à l'estimation de la biomasse et de l'architecture racinaire de deux espèces d'arbres légumineux. Un modèle racinaire fractal dont l'estimation des paramètres repose sur la théorie du « modèle vasculaire » a été appliqué à l'étude de l'architecture de Erythrina lanceolata et Gliricidia sepium cultivés dans des systèmes agroforestiers. Ce modèle a été confronté à un modèle fractal théorique dédié à la simulation du système vasculaire de plantes. La diminution de la section conductrice au niveau de chaque ramification demeure indépendante du diamètre, et peut-être considérée comme étant invariable à l'échelle de l'ensemble du système racinaire. Les valeurs des paramètres d'échelle sont approximativement équivalentes pour les deux espèces. La distance entre deux ramifications n'a pas pu être estimée à partir du deuxième modèle, aussi a-t-elle été estimée à partir d'une régression empirique. Un modèle empirique a également été utilisé pour l'estimation de la distribution des angles de ramifications. Ces modalités sont typiques d'interactions fortes avec les caractéristiques de l'environnement local, et leur modélisation nécessite une étude approfondie des interactions sol-racines. Cette étude débouche sur des considérations agronomiques qui montrent l'utilité d'approches architecturales pour l'amélioration de la gestion des interactions souterraines dans les systèmes agroforestiers.

Erythrina lanceolata / Gliricidia sepium / agroforesterie / modèle vasculaire / autosimilarité

\section{INTRODUCTION}

Root system studies are necessary for understanding the tree-crop interactions in agroforestry systems [15]. This objective calls for studies of three-dimensional (3D) root architecture, because sharing of soil space also strongly affects the sharing of soil resources [12].

Field description of root architecture is a challenging task, and most conventional root sampling techniques are inadequate. Auger sampling of known soil volumes provides reliable estimates of biomass and length distribution of fine roots [11, $18]$, but coarse roots are too sparsely situated in the soil to be reliably studied by this method; trench wall methods provide information on the local root distribution, but the laborious digging usually impedes the excavation of enough repetitions for quantitative estimates [3]; finally, the complete exposure of a root system provides all necessary information, but it may be prohibitively expensive if applied to several trees, and it may cause severe disturbance to the crop production. Due to these inadequacies, modelling techniques have been proposed to deal with the architectural description $[5,10]$. Parameterisation and validation of a root architecture model requires the excavation of complete root systems, or at least large representative parts of them, but in a smaller scale than in purely descriptive methods.

Van Noordwijk et al. [21, 25] proposed that fractal geometry combined with parameter estimation based on the pipe model theory [19] could be applied for describing tree root architecture. The pipe model of vascular plants is shown to be a special case of the more general fractal branching and scaling pattern in a

\footnotetext{
* Corresponding author: pekka.nygren@ @elsinki.fi
} 
variety of biological systems [26], and it thus is a valid basis for estimating the fractal parameters of a root system. Further, it has been proposed that based on fractal geometry assumptions, an index of tree root competitiveness may be estimated by exposing the proximal roots, or roots directly attached to the root collar, and measuring their vertical insertion angle and diameter. Competitiveness index is calculated as the ratio of the sum of squared diameters of horizontal roots (insertion angle $<45^{\circ}$ ) to the squared diameter of the stem [24]. If the fractal assumptions hold, the index provides a simple means to estimate tree root competitiveness.

The self-similarity principle [13] defines an object that maintains similar form over a range of scales. This principle applied to a tree root system predicts that roots follow the same bifurcation pattern from proximal roots to the smallest transport roots. Water and nutrient absorbing fine roots are not considered here, as they are functionally different from the water and nutrient transporting coarse roots and may follow different growth patterns [20]. The basic parameters of fractal root models describe the ratio of the sum of root cross-sectional areas after a bifurcation to the cross-sectional area before bifurcation, $\alpha$, and the distribution of the cross-sectional areas after bifurcation, $q[21,25]$.

Independency of ratios $\alpha$ and $q$ on root diameters has been observed in tropical legume trees over a large range of diameters $[16,23]$. However, large variability within the whole root system was observed, which affected the precision of the root length and biomass estimates and the architecture generated by the model. Further, the model had low aptitude for predicting root lengths, and other fitting possibilities need to be studied [16]. West et al. [27] presented a general fractal allometric model for vascular plants, which takes into account the tapering of the water conducting vessels. Model parameters are derived from fractal geometry and hydrodynamics rather than from empirical observations. The model has been developed for plant shoots. As transport roots form part of the same water conducting system, similar allometric principles should apply to root and shoot.

In addition to these aspects related to the improvement of $\alpha$, $q$ and root length prediction, there is a need to investigate the global relevance of these concepts when applied to other species. The objective of our contribution is to research the ways of improving the accuracy of the fractal root model as formulated by van Noordwijk et al. [21, 25] for describing the architecture of a tree root system, and predicting root biomass and length. We applied the model to two tropical legume trees, Erythrina lanceolata Standley (Papilionaceae: Phaseoleae) and Gliricidia sepium (Jacq.) Kunth ex Walp. (Papilionaceae: Robinieae). We also studied relationships between scaling parameters of the models of van Noordwijk et al. [21, 25] and West et al. [27], and the applicability of the latter for predicting average link length of lateral roots.

\section{MATERIALS AND METHODS}

\subsection{The fractal root models}

Topology of the root system of a G. sepium or an E. lanceolata was described as a network of connected links whose length and diameter are root order dependent $[21,25]$. At a given bifurcation event, a root segment, or link (order $n$, link $i$ ) is divided into several new links that forms the next higher order (order $n+1$, link $j$ ).

Root architecture is designed using a recursive algorithm [16]. The algorithm is applied until the final branch of the network, roots of minimum diameter $D_{\mathrm{m}}$ are reached. Here, we applied the $D_{\mathrm{m}}$ of $5 \mathrm{~mm}$. The scaling factor $\alpha$ is defined as the ratio of the square of root diameter before bifurcation $\left(D_{\mathrm{b}}^{2}\right)$ to the sum of squares of the diameters of bifurcating roots $\left(\Sigma D_{\mathrm{a}}^{2}\right)$ :

$$
\alpha=D_{\mathrm{b}}^{2} / \Sigma D_{\mathrm{a}}^{2} .
$$

The allocation factor of root cross-sectional area, $q$, is estimated:

$$
q=\max \left(D_{\mathrm{a}}^{2}\right) / \Sigma D_{\mathrm{a}}^{2} .
$$

Mathematical details are provided in [21, 25], and the model algorithm is described in [16].

Root bifurcation angle was estimated stochastically from field data. First, the relative frequency distribution of both vertical and horizontal bifurcation angles in $0.175 \mathrm{rad}\left(10^{\circ}\right)$ classes was generated from field data. From this distribution, the cumulative frequency range that corresponds to each class was computed. A random number between 0 and 100 was generated using the 'runif()' function of the S-Plus software [22]. The random number was compared with the cumulative frequency series, and the angle within the probability range of which the random number corresponded, was used as the angle of the following bifurcation. This algorithm provides reliable estimates of the root bifurcation angles independently of the form and density of the angle distribution, and no fitting of a theoretical distribution to data is necessary.

Full application of the model of West et al. [27] would require information on vessel diameter that was not available. However, scaling of the total cross-sectional area before and after bifurcation is comparable between the model presented above and that of West et al. [27]. The scaling is estimated:

$$
n A_{\mathrm{a}} / A_{\mathrm{b}}=n^{1-a}
$$

where $A_{\mathrm{a}}$ is the average cross-sectional area of bifurcating roots, $A_{\mathrm{b}}$ is the cross-sectional area before bifurcation, $n$ is the number of new links and $a$ is a scaling parameter. When $a$ is 1 , the model reduces to the classical area preserving pipe model [19]. The ratio $n A_{\mathrm{a}} / A_{\mathrm{b}}$ is equal to $\sum D_{\mathrm{a}}^{2} / D_{\mathrm{b}}^{2}$. Thus:

$$
\alpha^{-1}=n A_{\mathrm{a}} / A_{\mathrm{b}} \text {. }
$$

Introducing $\alpha$ to equation (3) gives:

$$
\alpha^{-1}=n^{1-a} \text {. }
$$

Equation (5) simplifies to:

$$
n^{a}=\alpha n
$$

The parameter $a$ is thus the $n$-based logarithm of the product $\alpha n$ :

$$
a=\log _{n} \alpha n \text {. }
$$

For a volume-filling network, the relationship between link length of order $i+1\left(l_{i+1}\right)$ and $i\left(l_{i}\right)$ is related to the number of new links $(n)$ [27]:

$$
l_{\mathrm{i}+1} / l_{\mathrm{i}}=n^{-1 / 3} \text {. }
$$

In this study, the value of $n$ is 2 for all applications of equations (3) to $(8)$

\subsection{Field observations for model parameterisation}

\subsubsection{Measurements}

Field measurements for model parameterisation differed slightly between E. lanceolata and G. sepium. However, the variables measured 
Table I. Chemical soil characteristics of the study sites.

\begin{tabular}{lccccc}
\hline Site & $\begin{array}{c}\mathrm{pH} \\
\text { in water }\end{array}$ & $\begin{array}{c}\text { Cation exchange } \\
\text { capacity }^{\mathrm{a}} \\
\left(\mathrm{cmol}[+] \cdot \mathrm{L}^{-1}\right)\end{array}$ & $\begin{array}{c}\text { Total } \\
\text { nitrogen } \\
\left(\mathrm{g} \cdot \mathrm{kg}^{-1}\right)\end{array}$ & $\begin{array}{c}\text { Available } \\
\text { phosphorus } \\
\left(\mathrm{mg} \cdot \mathrm{L}^{-1}\right)\end{array}$ & $\begin{array}{c}\text { Soil } \\
\text { order }\end{array}$ \\
\hline Quepos, Costa Rica & 5.3 & 29.9 & 1.5 & 9.1 & Inceptisol \\
Prise d'Eau, Guadeloupe & 6.1 & 17.5 & 2.3 & 85.8 & Oxisol \\
\hline
\end{tabular}

${ }^{\mathrm{a}}$ Ammonium acetate (pH 7) method; ${ }^{\mathrm{b}}$ Kjeldahl method; ${ }^{\mathrm{c}}$ Olsen method.

in exposed root systems were similar for both species: (i) link order and number following the topology presented in [16], (ii) link diameter before each bifurcation, and diameters of the bifurcating links, (iii) link length $L_{i}$, (iv) vertical and horizontal angle between the bifurcating links (bifurcation angle) to closest $10^{\circ}$, (v) stem diameter above the root collar of the measurement trees, and (vi) relationship between fresh root volume and dry mass.

\subsubsection{Erythrina lanceolata experiment}

The field data on Erythrina lanceolata was measured in the experimental farm of the Costa Rican Ministry of Agriculture and Animal Husbandry (MAG) close to Quepos, Costa Rica ( $9^{\circ} 26^{\prime} \mathrm{N}, 84^{\circ} 09^{\prime} \mathrm{W}$, $20 \mathrm{~m}$ asl.). In Damas $\left(9^{\circ} 03^{\prime} \mathrm{N}, 84^{\circ} 13^{\prime} \mathrm{W}, 6 \mathrm{~m}\right.$ a.s.l.), the closest meteorological station of the Costa Rican National Meteorological Institute, the 15-yr monthly average of temperature maxima vary from $30{ }^{\circ} \mathrm{C}$ (November) to $32{ }^{\circ} \mathrm{C}$ (February through April) and minima from $21{ }^{\circ} \mathrm{C}$ (January) to $23^{\circ} \mathrm{C}$ (April through June). Annual rainfall varies from 3000 to $4000 \mathrm{~mm}$, with a relatively dry season from January through March, when potential evapotranspiration exceeds precipitation. The soil characteristics are summarised in Table I.

Erythrina lanceolata was planted as a shade and support tree for vanilla (Vanilla planifolia L.) in 1993. Trees were planted over $2300 \mathrm{~m}^{2}$ on a $2 \times 3 \mathrm{~m}$ spacing $\left(1667\right.$ trees $\left.\cdot \mathrm{ha}^{-1}\right)$. About a quarter of the area was reserved for testing a vanilla variety new to the region, and the rest was used for commercial vanilla cultivation. Trees in the commercial plantation were partially pruned once or twice a year, and trees in the variety trial plot were pruned at a lower frequency. No prunings in the variety trial area were done during the two years preceding this study.

The plantation was divided into four plots of 99 trees in June 1997. Three pruning regimes of E. lanceolata were assigned to the plots: (i) complete pruning every six months (T-6), (ii) partial, ca. 50\%, pruning every three months (P-3), and (iii) an intact control (C). Under the fourth pruning regime, complete pruning every three months, all trees died within a year [2]. Pruned plots were situated in the commercial plantation area, and the control plot was situated in the vanilla variety trial.

Eighteen months after the beginning of the pruning regimes (November 1998), a tree from each regime (C, T-6 and P-3) was randomly selected for root architecture studies. The root system was completely exposed in a $90^{\circ}$ sector from the stem. The roots were carefully dug one by one in order to avoid changes in their position. The roots were exposed to the minimum diameter of $5 \mathrm{~mm}$, and the variables described above were measured.

In April 1999, three trees from each pruning treatment were randomly selected for a more detailed study of the proximal roots. All proximal roots were exposed. In addition to the data recorded for the roots in the complete root system exposure, the diameter difference between the point of insertion to root collar (below the initial thickening) and first bifurcation was recorded.

\subsubsection{Gliricidia sepium experiment}

Field data on Gliricidia sepium was measured at the experimental farm of the Antillean Research Centre of the Institut National de la Recherche Agronomique (INRA) in Prise d'Eau, Guadeloupe (16 $12^{\prime} \mathrm{N}$, $61^{\circ} 39^{\prime} \mathrm{W}, 125 \mathrm{~m}$ a.s.l.). The monthly average of temperature maxima varies from $28{ }^{\circ} \mathrm{C}$ (December through March) to $30^{\circ} \mathrm{C}$ (August through October) and minima from $19{ }^{\circ} \mathrm{C}$ (January) to $23{ }^{\circ} \mathrm{C}$ (June through September). Annual rainfall is ca. $2500 \mathrm{~mm}$, with a relatively equal distribution throughout a year, but potential evapotranspiration may exceed precipitation between January and April. The soil characteristics are summarised in Table I.

Gliricidia sepium was planted in May 1993 using stakes cut from a near-by living fence. Trees were planted over 0.4 ha on a $0.7 \times 3 \mathrm{~m}$ spacing (4 760 trees $\cdot \mathrm{ha}^{-1}$ ). Native Paspalum notatum Flügge dominated the grass layer (ca. $80 \%$ of grass biomass), with planted Digitaria decumbens Stent. as the second most common species. The experiment was managed uniformly by means of partial prunings every 3-6 months according to the growth of trees, in order to avoid excessive shading of the grass.

In March 1997, two plants of G. sepium were selected for the architectural description of the root systems. They were excavated with a digger, in a sphere of 1.5-2 $\mathrm{m}$ of radius, and $0.8-1 \mathrm{~m}$ depth, and then washed in order to separate roots from soil particles. On June 1997, the root systems of four other trees were carefully removed by hand in a $16 \mathrm{~m}^{2}$ delimited trench, after having been over-flooded the day before. This method allowed measurements of more accurate information on in situ root systems, particularly on undisturbed root angles. Observations were carried out to $0.8 \mathrm{~m}$ depth.

After the excavation, link lengths and extreme diameters were measured for all intact root segments, in relation with their order and link number, until the seventh order. The consistency between the measurements of the radial and insertion angles measured before and after excavation was tested. Due to the lignified structure of the roots, there were no discrepancies between the two series of measurements. Calculation of coefficients $\alpha$ and $q$ was made on the same data set.

\section{RESULTS}

\subsection{Parameter estimation from field data}

Uniformity of the scaling factor $\alpha$ and allocation factor $q$ (Eqs. (1) and (2), respectively) within the root systems of E. lanceolata and G. sepium was tested with respect to link diameter before bifurcation and link order (Fig. 1). The differences in the values of $\alpha$ and $q$ between link orders 1, 2, 3 and $\geq 4$ were tested by analysis of variance for whole data set, and by orthogonal contrasts for the differences between selected pairs of link orders. The effect of link diameter on the parameters was studied by linear regression. 
E. lanceolata
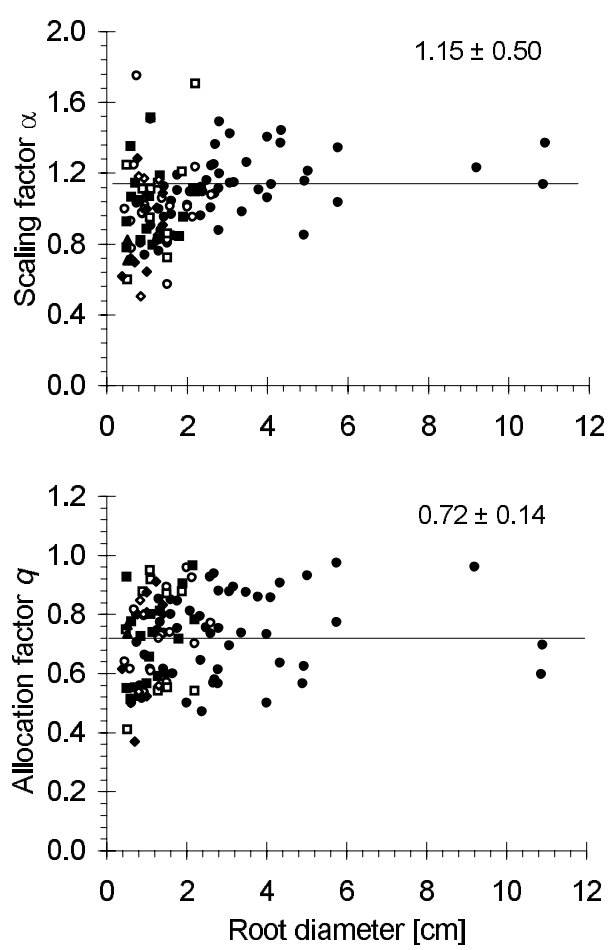

Link order: $\bullet 1 \circ 2 \cdot 3 \div 4 \cdot 5 \bullet 6 \bullet 7$
G. sepium
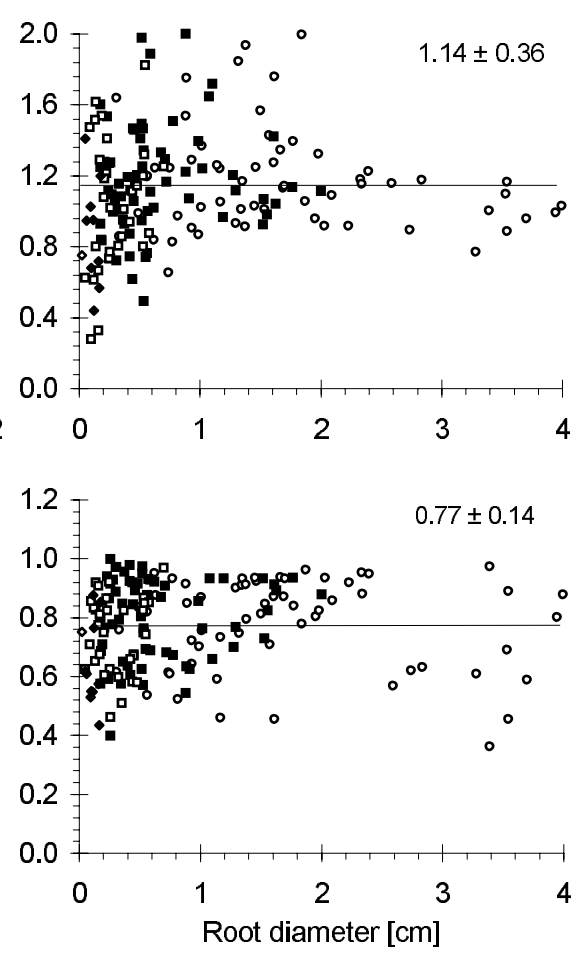

Figure 1. The scaling factor $\alpha$ (top) and allocation factor $q$ (bottom) as a function of root diameter and link order in Erythrina lanceolata (left) and Gliricidia sepium (right). The numbers in the upper right corner of each plot are general mean \pm standard deviation. The mean is also displayed by the horizontal line in each plot.

No significant differences were detected in the value of $\alpha$ between the link orders, and the proportion of explained variance, $r^{2}$, was 0.02 for both species. The regression between link diameter and $\alpha$ was not significant for $E$. lanceolata $(P=0.087$, $\left.r^{2}=0.02\right)$, nor for $G$. sepium $\left(P=0.921, r^{2}=0.00\right)$. In $G$. sepium, significant differences in the value of $q$ were detected between link orders, but the $r^{2}$ was low at 0.06 . In E. lanceolata, the value of $q$ did not show any dependence on link order $(P=$ $0.991)$. The regression between link diameter and $q$ was not significant for either species $\left(P=0.081, r^{2}=0.03\right.$ and $P=0.181$, $r^{2}=0.01$ for $E$. lanceolata and $G$. sepium, respectively). These analyses indicated that the variation observed in the values of $\alpha$ and $q$ (Fig. 1) is random, and we decided to use the general average values for the whole root system. The $\alpha$ values for E. lanceolata and G. sepium, 1.15 and 1.14, respectively, correspond to value 1.19 for parameter $a$ in the model of West et al. [27], when two new links are formed in each bifurcation $(n=2$ in Eqs. (3-7)).

In E. lanceolata, the average link length varied from $15 \mathrm{~cm}$ in order 6 to $75.7 \mathrm{~cm}$ in order 1 . In G. sepium, the average link length varied from $2 \mathrm{~cm}$ in order 7 to $39.3 \mathrm{~cm}$ in order 1. Erythrina lanceolata had more proximal roots than G. sepium, and they were thicker in root collar (Tab. II). There was large variation in proximal root length of both species but, on average, the proximal roots of E. lanceolata were twice as long as those of G. sepium.

Two models were fitted to the data on observed average link length. Observed length of proximal roots (order 1) was used as the starting point for the theoretical volume-filling estimate (Eq. (7)). The estimated length of order 2 was used for estimating length of order 3 , and the procedure was repeated until order 7 (Fig. 2). An empirical logarithmic regression was also fitted to the data (Tab. II). The fit of the empirical regression was excellent for G. sepium and satisfactory for E. lanceolata from link order 1 through 7 (Tab. II and Fig. 2). Because the volume-filling model used the observed length of order 1 as starting point, its fit was evaluated for orders 2 through 7, the lengths of which were real estimates. The proportion of explained variance, $r^{2}$, of the volume-filling model was 0.43 for $G$. sepium and 0.57 for E. lanceolata. The $r^{2}$ values of the empirical model for orders 2 through 7 were 0.98 and 0.62 for G. sepium and E. lanceolata, respectively. Because of the better fit, the empirical model was used for estimating link length in all simulations reported here.

In $86.4 \%$ of all root bifurcation events in E. lanceolata and $90 \%$ in G. sepium, only one lateral root bifurcated from the main axis. In all other events in E. lanceolata, two laterals were formed, while a few cases with more than two laterals were observed in G. sepium. 
Table II. Selected root architecture characteristics of Erythrina lanceolata and Gliricidia sepium.

\begin{tabular}{lcc}
\hline Characteristic & E. lanceolata & G. sepium \\
\hline Proximal roots & & $9.8 \pm 3.00(n=6)$ \\
Mean number per tree $\pm \mathrm{SD}$ & $13.0 \pm 2.00(n=9)$ & $2.3 \pm 0.92(n=49)$ \\
Mean diameter $\pm \mathrm{SD}(\mathrm{cm})$ & $3.4 \pm 1.98(n=118)$ & $39.3 \pm 15.5(n=31)$ \\
Mean length $\pm \mathrm{SD}(\mathrm{cm})$ & $75.7 \pm 38.8(n=27)$ & $M_{\mathrm{r}}=0.63 \times V_{\mathrm{r}}$ \\
Root dry mass $\left(M_{\mathrm{r}}\right.$ in $\left.\mathrm{g}\right)$ & $M_{\mathrm{r}}=0.32 \times V_{\mathrm{r}}$ & $r^{2}=0.99$ \\
- root volume $\left(V_{\mathrm{r}}\right.$ in cm $\left.\mathrm{cm}^{3}\right)$ relationship & $r^{2}=0.97$ & $L_{\mathrm{i}}=40.82-20.41 \times \ln (i)$ \\
Empirical link length $\left(L_{\mathrm{i}}\right.$ in cm) & $L_{\mathrm{i}}=74.24-27.47 \times \ln (i)$ & $r^{2}=0.99$ \\
- root order $(i)$ relationship & $r^{2}=0.85$ & $0.89 \pm 0.13(\mathrm{n}=5)$ \\
Mean of competitiveness index $\pm \mathrm{SD}$ & $0.75 \pm 0.17(n=9)$ &
\end{tabular}
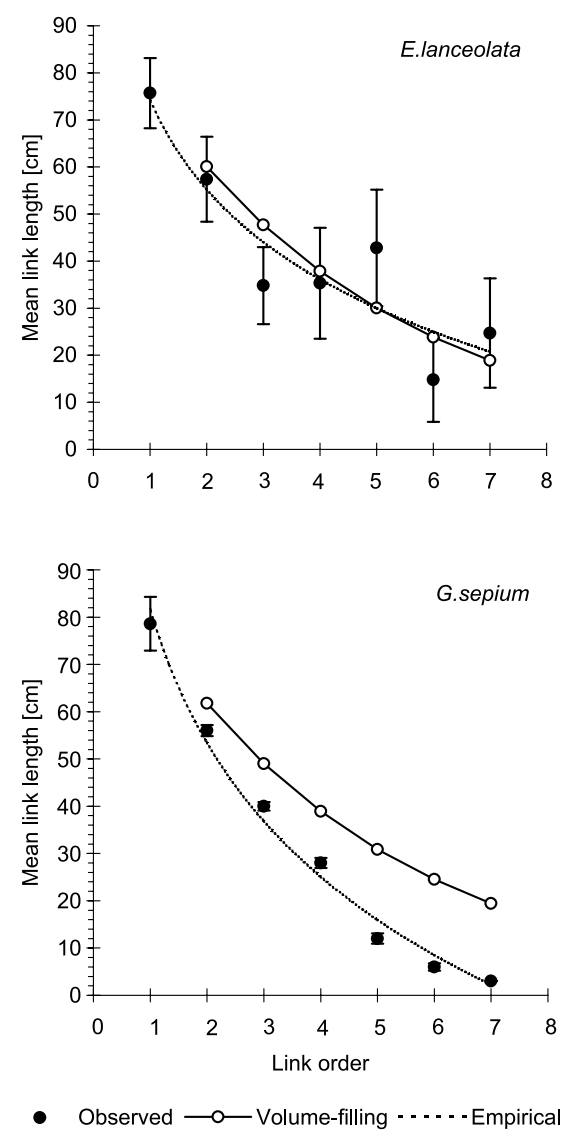

Figure 2. Comparison of the volume-filling (Eq. (8)) and empirical (Tab. II) model estimates for average link length with observed values in Erythrina lanceolata (top) and Gliricidia sepium (bottom). The error bars indicate the SEM for observed values.

The vertical bifurcation angle distributions differed strongly between the two legume tree species. In E. lanceolata, laterals continued the growth in the same soil horizon as the main root in more than half of the bifurcations. Almost no roots were oriented up from the main link (Fig. 3). In G. sepium, the vertical angles were quite evenly distributed over the whole range from negative (down) to positive (up) straight angle. The horizontal bifurcation angle was $\leq 0.175 \mathrm{rad}\left(10^{\circ}\right)$ in ca. $40 \%$ of bifurcation events in both species; the rest were quite evenly distrib- uted between 0.349 and 1.571 rad (Fig. 3). Neither vertical nor horizontal bifurcation angle distribution was normal (ShapiroWilk test at $0.1 \%$ ). Attempts to fit skewed theoretical distributions like gamma and Weibull distribution to the bifurcation angle data also failed, and the bifurcation angle was estimated stochastically from the data in Figure 3 using the procedure described in Section 2.1.

Proximal roots of E. lanceolata were conic (Fig. 4). A strong regression between the squared root diameter at root collar and the squared root diameter at first bifurcation was observed, although there were a few roots shorter than $40 \mathrm{~cm}$ without any conicity. The conicity of the proximal roots of G. sepium was not significant; hence, it was not included in the simulation model. The regression between the root volume and root dry mass was strong (Tab. II) for both tree species.

Linear regression between the squared stem diameter and the sum of squared proximal root diameters was significant $(P<0.001)$ for both species, but the regression coefficient was much higher for $G$. sepium than for E. lanceolata (Fig. 5). The size differences between the two legume tree species were apparent: the maximum squared stem diameter was five times, and the sum of squared proximal root diameters was four times bigger in E. lanceolata than G. sepium (Fig. 5).

Competitiveness index was calculated as the ratio of the sum of squared diameters of horizontal roots (insertion angle $<45^{\circ}$ ) to the sum of squared diameter of all proximal roots. The proximal roots of E. lanceolata were more vertically oriented than in G. sepium, which was also reflected in competitiveness indices (Tab. II). Mean \pm SD of the index for E. lanceolata was $0.75 \pm 0.17$ and $0.89 \pm 0.13$ for $G$. sepium. By pruning regime, the mean \pm SD of competitiveness index in E. lanceolata was higher in the intact trees, $0.87 \pm 0.03$, than under P-3 and T-6 pruning regimes, $0.68 \pm 0.09$ and $0.69 \pm 0.26$, respectively.

\subsection{Model results}

In the simulations, the link diameter was generated according to the bifurcation rules determined by equations (1) and (2). Thus, comparison of observed and simulated average link diameters provides a test of the accuracy of the simulations. Because the first order or proximal root diameters were based on field data, the comparison was made from second order roots to the highest order with enough field data for calculating standard deviations when the E. lanceolata data was divided by pruning 

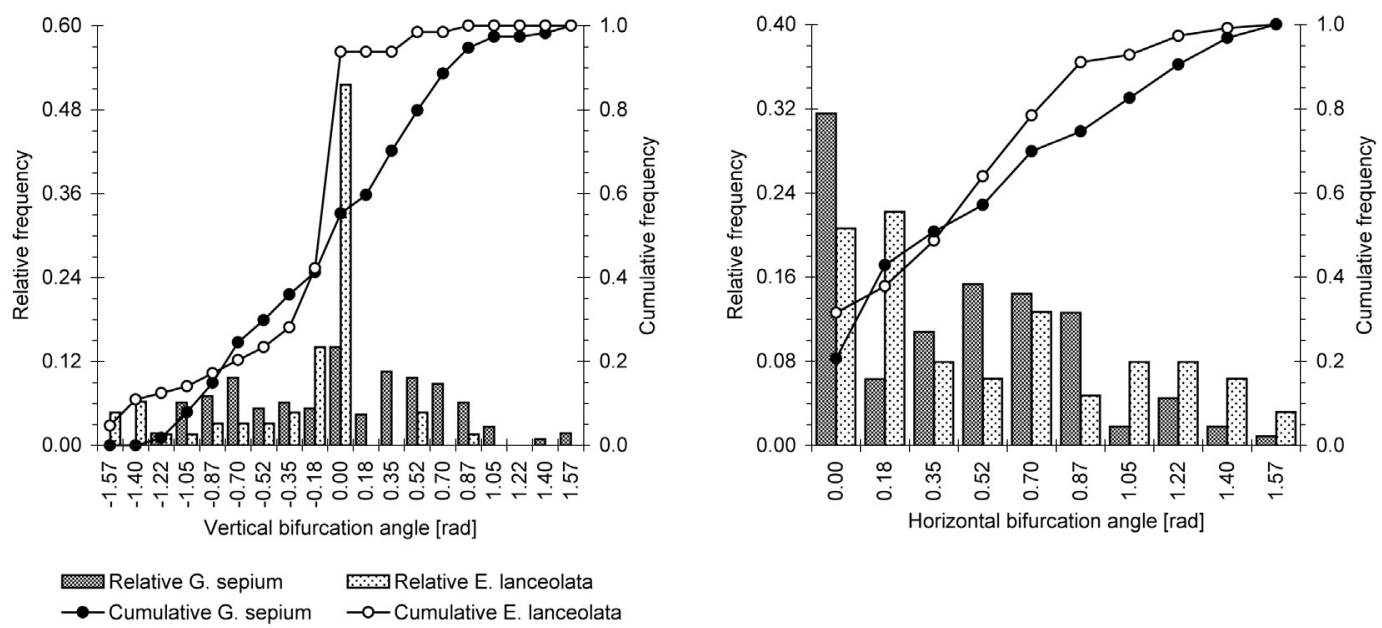

Figure 3. Relative frequency distribution of vertical (left) and horizontal (right) root bifurcation angles in Erythrina lanceolata and Gliricidia sepium.

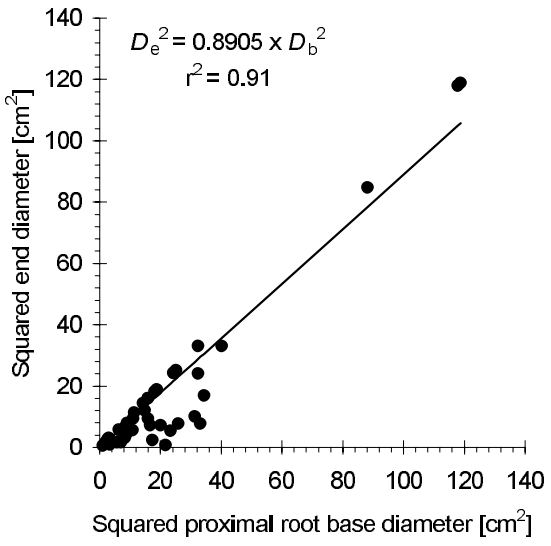

Figure 4. Observed and estimated relationship between the squared diameter at the point of insertion to root collar, the base $\left(D_{\mathrm{b}}^{2}\right)$, and at the first bifurcation, the end $\left(D_{\mathrm{e}}^{2}\right)$, in proximal roots of Erythrina lanceolata.

regime (Fig. 6). Simulated and observed values were similar. However, second order links of P-3 and intact E. lanceolata were overestimated. None of the differences between simulated and observed values was significant according to the Student's $t$-test at $5 \%$

The differences in the simulated root biomass, root length and number of links between pruning regimes of $E$. lanceolata were tested by analysis of covariance, in which the pruning regime was the class variable and the number of proximal roots was used as covariable, followed by Duncan's Multiple Range Test at 5\%. Simulated root biomass, total root length and number of links were significantly higher in the intact trees than under either pruning regimes (Tab. III). No significant differences were found without the covariable.

According to the simulations, the root system of E. lanceolata appears to be quite deep; most simulations produced root systems about $2.0 \mathrm{~m}$ deep, although some deeper individual roots were produced in the intact trees. Simulation on G. sepium typically resulted in about $1.0 \mathrm{~m}$ deep root systems. The horizontal radius
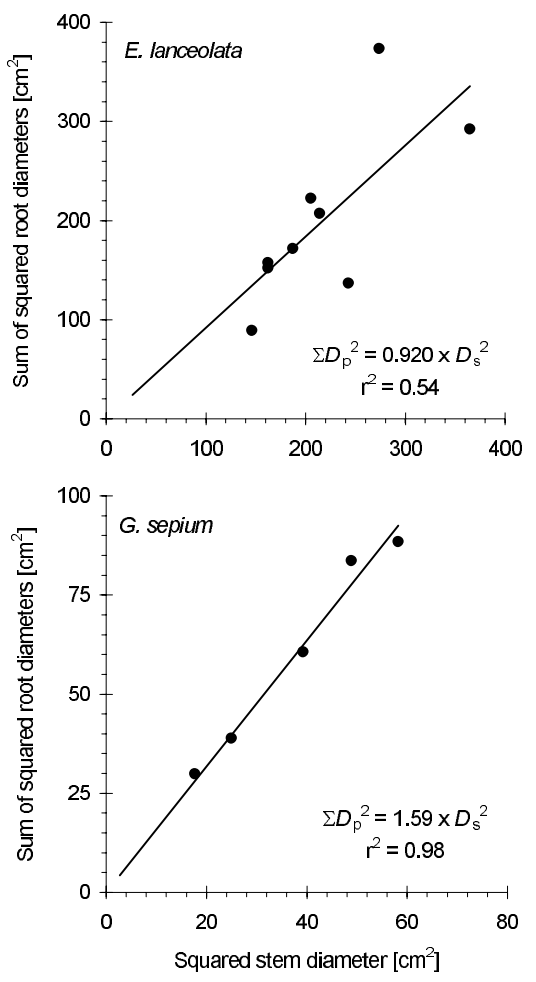

Figure 5. Relationship between the squared stem diameter, $D_{\mathrm{s}}^{2}$, and the sum of squared proximal root diameters, $\Sigma D_{\mathrm{p}}^{2}$, in Erythrina lanceolata (top) and Gliricidia sepium (bottom).

of the root system of an E. lanceolata tree was typically between 2.0 and $3.0 \mathrm{~m}$, and of a G. sepium between 1.5 and $2.5 \mathrm{~m}$. The main roots followed quite a superficial pattern in both species, but lower order links were quite deep.

The estimated radius of the root system of each E. lanceolata tree reached the root collar area of two other trees (Fig. 7). Assuming the average radius of $2.18 \mathrm{~m}$ (e.g. tree 6 in Fig. 7), 

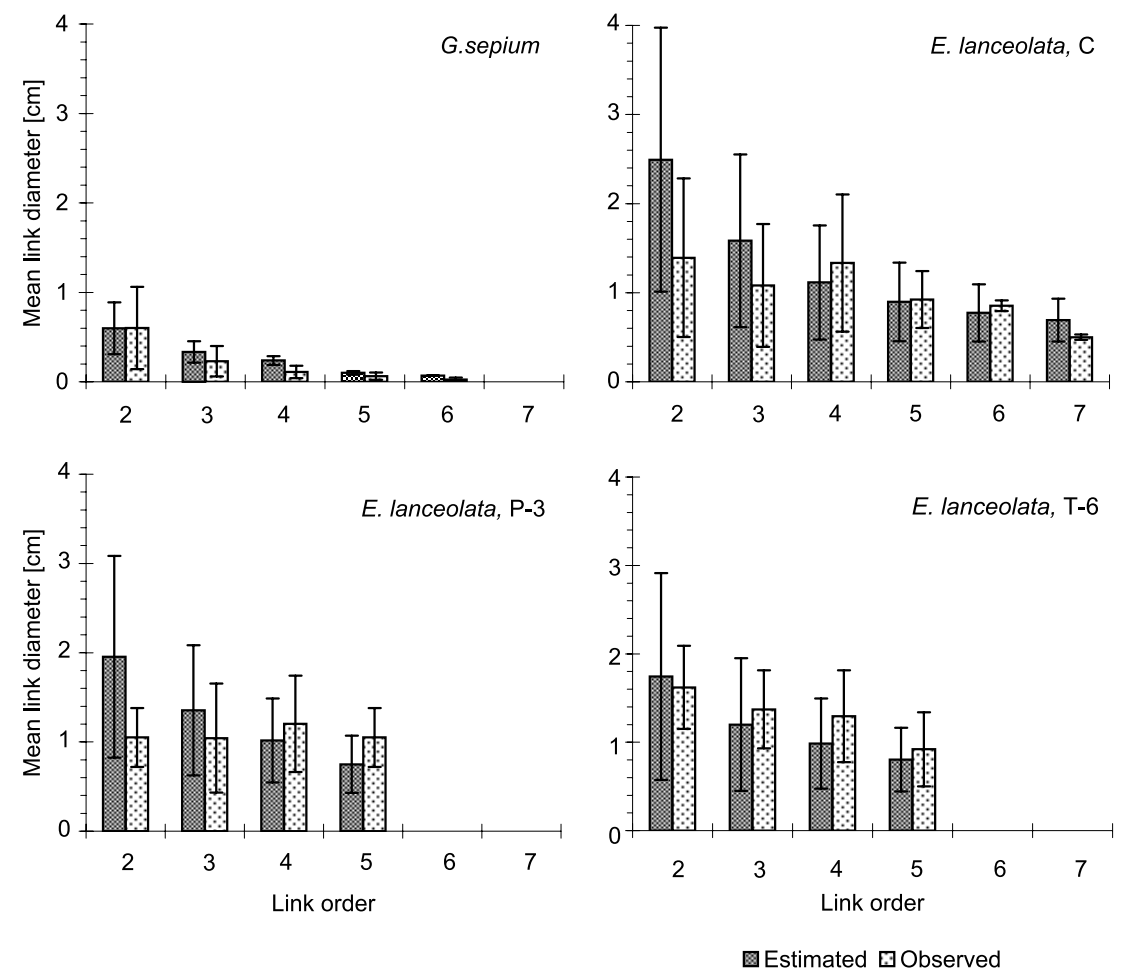

Figure 6. Estimated and observed mean root diameter by root order in Gliricidia sepium and under three pruning regimes in Erythrina lanceolata $(\mathrm{C}=$ unpruned control, $\mathrm{P}-3=$ about $50 \%$ pruning every three months, and T- $6=$ complete pruning every six months $)$. The error bars indicate standard deviations.

Table III. Simulated mean \pm standard deviation of total root system mass, length and number of links in Erythrina lanceolata under three pruning regimes $(\mathrm{C}=$ intact control, $\mathrm{P}-3=50 \%$ pruning every three months, $\mathrm{T}-6=$ total pruning every six months). The means within a column followed by the same letter do not differ significantly if the observed number of proximal roots for each simulated tree is used as covariable (Duncan's Multiple Range Test at 5\%). The simulations were conducted based on measured proximal root diameters of three trees per pruning regime.

\begin{tabular}{lcccc}
\hline Pruning regime & $\begin{array}{c}\text { Number of } \\
\text { proximal roots }\end{array}$ & $\begin{array}{c}\text { Root mass } \\
{[\mathrm{kg}]}\end{array}$ & $\begin{array}{c}\text { Root length } \\
{[\mathrm{m}]}\end{array}$ & Number of links \\
\hline C & $12.7 \pm 2.89$ & $12.95 \pm 4.42 \mathrm{a}$ & $223 \pm 59.2 \mathrm{a}$ & $828 \pm 256 \mathrm{a}$ \\
P-3 & $13.3 \pm 2.52$ & $7.46 \pm 0.48 \mathrm{~b}$ & $176 \pm 36.1 \mathrm{~b}$ & $587 \pm 115 \mathrm{~b}$ \\
T-6 & $13.3 \pm 2.31$ & $6.85 \pm 2.99 \mathrm{~b}$ & $158 \pm 50.1 \mathrm{~b}$ & $517 \pm 188 \mathrm{~b}$ \\
\hline
\end{tabular}

the root system of each tree would have some overlap with the root systems of 10 other trees under the illustrated P-3, which had intermediate total root length among the studied pruning regimes (Tab. III). The estimated radius of the root system of each G. sepium tree reached the root collar area of five other trees (Fig. 7). Assuming the average radius of $1.55 \mathrm{~m}$, the root system of each tree would have some overlap with the root systems of 15 other trees.

\section{DISCUSSION}

\subsection{Fractal scaling of root system}

Values of the scaling parameter $\alpha(1.15$ and 1.14 for G. sepium and E. lanceolata, respectively) and allocation parameter $q(0.72$ and 0.77$)$ were very similar. General root architecture of the two species was quite similar, best described as dichotomous with uneven link diameters. This suggests that this kind of root architecture scales with approximately equal parameters in different tree species. However, van Noordwijk and Purnomosidhi [23] found general mean \pm SD of $1.33 \pm$ 0.538 for $\alpha$ in 29 multipurpose tree individuals that belonged to 19 species. They did not discuss any trends in relation to general root architecture. The general mean \pm SD of $q$ was $0.86 \pm 0.148$. The values of $\alpha$ and $q$ did not depend on link order or diameter in our study nor in [23].

The model of West et al. has been applied for scaling root biomass [8], but the scaling of vascular system is derived only for shoots [27]. We found a close relationship between the values of parameter $\alpha$ of van Noordwijk et al. [21, 25] and $a$ of West et al. [27]. This implies the latter model may be applied 

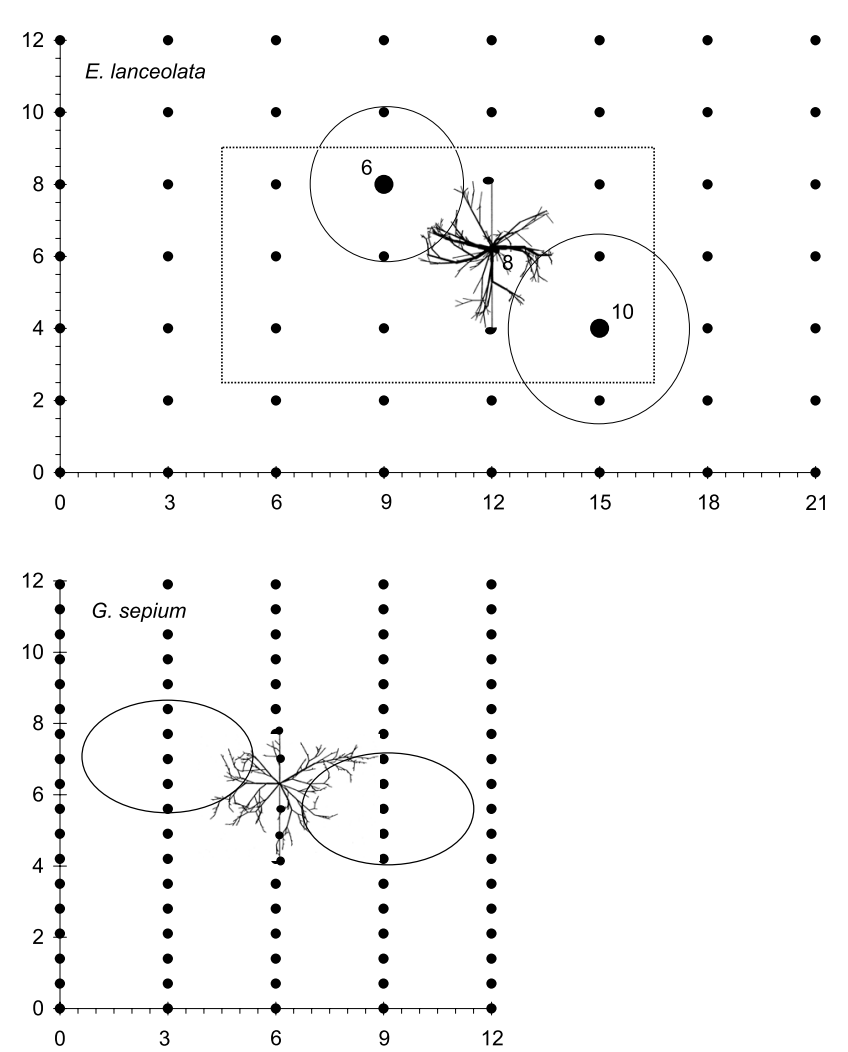

Figure 7. Schematic presentation on the horizontal extension of the root systems of three Erythrina lanceolata trees under the P-3 pruning regime (50\% pruning every three months; top), and three Gliricidia sepium trees (bottom). For E. lanceolata, the simulated root architecture of tree 8 is shown, and the ellipses refer to the simulated root extension in trees 6 and 10, the small dots refer to other trees and the rectangle is the 12-tree sample plot. For G. sepium, the simulated root architecture of a tree is shown, and the ellipses refer to the simulated root extension in two other trees and the small dots refer to other trees.

to tree roots, but actual measurements of vessel diameter are required for its full evaluation.

Contrary to the good agreement of the models of van Noordwijk et al. [21, 25] and West et al. [27] with data in predicting the scaling of link diameter, the theoretical volume-filling model (Eq. (8)) poorly explained the link length in G. sepium. Although the fit was better in E. lanceolata, in both cases an empirical logarithmic regression fitted to the actual link length data gave the best fit (Fig. 2).

\subsection{Root bifurcation angle}

Attempts to use theoretical distributions for predicting root bifurcation angle failed. Only the stochastic algorithm based on observed bifurcation angle distribution worked well. Further, differences in bifurcation angle distribution, especially vertical angles, produced the main architectural differences between the two species studied. While link diameter relationships before and after a bifurcation can be derived from hydrodynamics [27] and they appear to be genetically determined by the properties of the vascular tissue [reviewed in 29], bifurcation angles may respond to the patchy soil environment where water and nutri- ents are unequally distributed. Several studies [1, 4, 9, 12, 28] indicate preferential root growth towards nutrient rich patches in soil. We may thus hypothesise that root bifurcation angles are strongly modified by responses to the soil environment and morphological plasticity of the roots.

\subsection{Root competitiveness index}

The root competitiveness index calculated as the relationship between the sum of squared diameters of horizontal proximal roots and squared stem diameter [24], or between the squared diameters of horizontal and all proximal roots is based on the assumption that the roots continue to grow in the same direction as observed close to the root collar. The assumption seemed to hold for E. lanceolata, lateral roots of which continued growth in the same soil horizon as the main root. In G. sepium, lateral roots tended to grow up or downwards from the main roots (Fig. 3). The usefulness of a competitiveness index based on proximal roots seems to depend on the general architecture of the tree root system. Considering the potential plasticity of the root system architecture in response to the soil environment, the evaluation of the usefulness of the index requires more field research.

The squared stem diameter was strongly correlated with the sum of squared proximal root diameters in G. sepium, but the regression was weak in E. lanceolata (Fig. 5). This may have been caused by formation of heartwood in older and bigger E. lanceolata trees. After the formation of heartwood begins, the simple pipe model relationship holds only if applied to sapwood relationships [29]. Thus, it was also justified to replace the squared stem diameter by the sum of squared diameters of all proximal roots in the calculation of the competitiveness index.

Van Noordwijk and Purnomosidhi [23] calculated the ratio of the sum of squared vertical root diameters to sum of squared diameters of all proximal roots of 19 multipurpose tree species in Southeast Asia. This index can be converted to the competitiveness index used in this study (Tab. II) by subtracting it from one. Only six species out of 19 had an index below 0.5, i.e. majority of their roots were vertical. Erythrina lanceolata would rank between the tenth and 11th most shallow root system in [23], or close to the average. Gliricidia sepium studied in Indonesia ranked the ninth most shallow, while G. sepium in Guadeloupe (this study) would rank between third and fourth in [23].

\subsection{Considerations for agroforestry practices}

Roots of both $G$. sepium and $E$. lanceolata overlapped between individual trees in the studied spatial arrangements (Fig. 7), suggesting intra-row competition between the trees. Root system overlap was more important in the bigger E. lanceolata. The root systems of E. lanceolata grown in $2 \times 3 \mathrm{~m}$ spacing were relatively circular (Fig. 7), while the denser G. sepium rows $(0.7 \times 3 \mathrm{~m})$ reduced root extension within row and increased occupation of the inter-row spaces (Fig. 7). Roots of both species occupied completely the inter-row, or crop, space. This may have both positive and negative consequences for crop production in agroforestry systems. Presence of G. sepium roots appears to enrich soil with $\mathrm{N}$ [6], but trees may compete for other nutrients and water with the crop. Dinitrogen fixation in E. lanceolata seems to be sensitive to shoot pruning [17], and competition even for soil $\mathrm{N}$ may occur following the pruning [14]. 
Both partial and complete pruning appeared to restrict root growth in E. lanceolata (Tab. III). This probably reflects the whole life history of $E$. lanceolata in the study site; intact trees had been growing without pruning since establishment of the plantation, while both pruned treatments were also pruned earlier. The 18-month-period of current pruning practices was not long enough to produce significant differences in coarse root biomass or length between the partial and complete pruning treatments. Both foliage production and fine root biomass were significantly lower under complete than partial pruning management [2]. The latter are sensitive indicators on short-term stress, and it appears that the coarse root biomass and general root architecture respond conservatively to tree management.

\subsection{Concluding remarks}

Root systems of both G. sepium and E. lanceolata appeared to be fractal. Both the scaling parameter $\alpha$ and allocation parameter $q$ had about the same value in both species. The theoretical model based on volume-filling fractals [27] failed to fit to the data on link length, and an empirical regression describing the link length as a function of link order best fitted to the data. Root bifurcation angles seemed to respond flexibly to soil environment and attempts to fit any theoretical distribution or regression for estimating them failed. It is possible that proper modelling of link length and bifurcation angle requires consideration of root functions and their response to local soil environment. Lateral roots of E. lanceolata continued their growth in the same soil layer as the main root, but laterals of G. sepium often grew towards different soil horizons. The latter observation casts some doubt on the validity of the root competitiveness index that is based on the vertical orientation of proximal roots. Root systems of both species also occupied the crop growing space in the studied agroforestry practices. Pruning management appeared to check coarse root growth over medium-term, but no short-term effects of pruning on coarse root biomass and architecture were detected. The simple fractal root model of van Noordwijk et al. [21, 25, see also 16] applied in this study appears to be practical for root studies in agroforestry. The application of the general fractal allocation model of West et al. [7, 8, 26, 27] to root systems also seems to be worth of further research.

Acknowledgements: We thank Ing. Agr. José Mattey Fonseca, director of the MAG experimental station in Quepos, Prof. Carlos Ramírez and Dr Frank Berninger for good cooperation during the field work, and Mr Asdruval Chacón for field assistance. The study was financed by the Academy of Finland (Research Grant 28203).

\section{REFERENCES}

[1] Arredondo J.T., Johnson D.A., Root architecture and biomass allocation of three range grasses in response to nonuniform supply of nutrients and shoot defoliation, New Phytol. 143 (1999) 373-385.

[2] Berninger F., Salas E., Effects of pruning intensity on biomass dynamics in Erythrina lanceolata, Agrofor. Syst. 57 (2003) 19-28.

[3] Böhm W., Methods of studying root systems, Springer-Verlag, Berlin, Germany, 1979, 188 p.

[4] Crick J.C., Grime J.P., Morphological plasticity and mineral nutrient capture in two herbaceous species of contrasted ecology, New Phytol. 107 (1987) 453-460.

[5] De Reffye P., Houllier F., Blaise F., Barthélémy D., Dauzat J., Auclair D., A model simulating above- and below-ground tree architecture with agroforestry applications, Agrofor. Syst. 30 (1995) 175-197.

[6] Dulormne M., Sierra J., Nygren P., Cruz P., Nitrogen-fixation dynamics in a cut-and-carry silvopastoral system in the subhumid conditions of Guadeloupe, French Antilles, Agrofor. Syst. 59 (2003) 121-129.

[7] Enquist B.J., Cope's Rule and the evolution of long-distance transport in vascular plants: allometric scaling, biomass partitioning and optimization, Plant Cell Environ. 26 (2003) 151-161.

[8] Enquist B.J., Niklas K.J., Global allocation rules for patterns of biomass partitioning in seed plants, Science 295 (2002) 1517-1520.

[9] Gersani M., Sachs T., Development correlations between roots in heterogeneous environments, Plant Cell Environ. 15 (1992) 463-469.

[10] Jourdan C., Rey H., Guédon Y., Architectural analysis and modelling of the branching process of the young oil-palm root system, Plant Soil 177 (1995) 63-72.

[11] Lehmann J., Zech W., Fine root turnover of irrigated hedgerow intercropping in Northern Kenya, Plant Soil 198 (1998) 19-31.

[12] Lynch J., Root architecture and plant productivity, Plant Physiol. 109 (1995) 7-13.

[13] Mandelbrot B.B., The fractal geometry of nature, Freeman, New York, USA, 1983, 468 p.

[14] Nygren P., Above-ground nitrogen dynamics following the complete pruning of a nodulated woody legume in humid tropical field conditions, Plant Cell Environ. 18 (1995) 977-988.

[15] Ong C.K., Corlett J.E., Singh R.P., Black C.R., Above- and belowground interactions in agroforestry systems, For. Ecol. Manage. 45 (1991) 45-57.

[16] Ozier-Lafontaine H., Lecompte F., Sillon J.-F., Fractal analysis of the root architecture of Gliricidia sepium for the spatial prediction of root branching, size and mass. Model development and evaluation in agroforestry, Plant Soil 209 (1999) 167-180.

[17] Salas E., Nygren P., Domenach A.M., Berninger F., Ramírez C., Estimating biological $\mathrm{N}_{2}$ fixation by a tropical legume tree using the non-nodulating phenophase as the reference in the ${ }^{15} \mathrm{~N}$ natural abundance method, Soil Biol. Biochem. 33 (2001) 1859-1868.

[18] Schroth G., Zech W., Above- and below-ground biomass dynamics in a sole cropping and an alley cropping system with Gliricidia sepium in the semi-deciduous rainforest zone of West Africa, Agrofor. Syst. 31 (1995) 181-198.

[19] Shinozaki K., Yoda K., Hozumi K., Kira T., A quantitative analysis of plant form - the pipe model theory. I. Basic analyses, Jap. J. Ecol. 14 (1964) 97-105.

[20] Sievänen R., Nikinmaa E., Nygren P., Ozier-Lafontaine H., Perttunen J., Hakula H., Components of functional-structural tree models, Ann. For. Sci. 57 (2000) 399-412.

[21] Spek L.Y., van Noordwijk M., Proximal root diameters as predictors of total root system size for fractal branching models. II. Numerical model, Plant Soil 164 (1994) 119-127.

[22] S-Plus User's Manual, Statistical Sciences, Inc., Seattle, WA, USA, 1991.

[23] Van Noordwijk M., Purnomosidhi P., Root architecture in relation to tree-crop-soil interactions and shoot pruning in agroforestry, Agrofor. Syst. 30 (1995) 161-173.

[24] Van Noordwijk M., Lawson G., Soumaré A., Groot J.J.R., Hairiah K., Root distribution of trees and crops: Competition and/or complementarity, in: Ong C.K., Huxley P. (Eds.), Tree-crop interactions: a physiological approach, CAB International, Wallingford, UK, 1996, pp. 319-364.

[25] Van Noordwijk M., Spek L.Y., De Willingen P., Proximal root diameters as predictors of total root system size for fractal branching models. I. Theory, Plant Soil 164 (1994) 107-118.

[26] West G.B., Brown J.H., Enquist B.J., A general model for the origin of allometric scaling laws in biology, Science 276 (1997) 122-126.

[27] West G.B., Brown J.H., Enquist B.J., A general model for the structure and allometry of plant vascular systems, Nature 400 (1999) $664-667$.

[28] Zhang H., Forde B.G., An Arabidopsis MADS box gene that controls nutrient-induced changes in root architecture, Science 279 (1998) 407-409.

[29] Zimmermann M.H., Xylem structure and the ascent of sap, Springer-Verlag, Berlin, Germany, 1983, 143 p. 